\title{
Aplikasi Computer Assisted Instruction (CAI) Pengenalan Hewan Berdasarkan Klasifikasi Makanan untuk Anak Berkebutuhan Khusus
}

\author{
Hubertus Cahyo $\mathrm{Argo}^{\# 1}$, Rudi Dwi Nyoto ${ }^{\# 2}$, Hafiz Muhardi ${ }^{\# 3}$ \\ \#Program Studi Sarjana Informatika Fakultas Teknik Universitas Tanjungpura \\ Jl. Prof. Dr. H. Hadari Nawawi, Pontianak 78124 \\ ${ }^{1}$ hubertuscahyoargo@gmail.com \\ ${ }^{2}$ rudydneinformatika.untan.ac.id \\ ${ }^{3}$ hafizmeinformatika.untan.ac.id
}

\begin{abstract}
Abstrak - Anak berkebutuhan khusus (ABK) adalah anakanak abnormal yang menyandang ketunaan. Computer Assisted Instruction (CAI) adalah media bantu pembelajaran yang menempatkan komputer sebagai piranti sistem pembelajaran individual, siswa dapat berinteraksi langsung dengan sistem komputer yang dirancang. Dalam proses pembelajaran di sekolah berkebutuhan khusus, salah satu pembelajaran yang diajarkan adalah pengenalan tentang hewan dalam mata pelajaran IPA. Materi pengenalan hewan juga diajarkan dalam terapi wicara untuk anak berkebutuhan khusus. Pada proses materi pengenalan hewan terkadang anak berkebutuhan khusus mengalami kesulitan untuk memahami materi tersebut. Beberapa anak berkebutuhan khusus juga terkadang mengalami kesulitan dalam mengeja dan melafalkan nama hewan yang akan mereka pelajari. Selama ini alat penunjang yang guru gunakan hanya buku lembar kerja siswa (LKS) dan buku yang khusus memuat materi tentang pengenalan hewan. Untuk kasus tertentu, para terapis untuk anak berkebutuhan khusus menggunakan alat bantu berupa kartu bergambar untuk mengenalkan hewan-hewan yang akan dipelajari anak berkebutuhan khusus. Tujuan dari penelitian ini adalah untuk membantu anak berkebutuhan khusus lebih mudah belajar dan mengenali hewan, serta mengenalkan pelafalan nama hewan dan suara hewan tersebut dengan memanfaatkan konsep CAI dengan model tutorial dan instructional games. Pengujian aplikasi menggunakan uji validasi yaitu ahli materi (Guru SBK Bina Anak Bangsa), serta pengujian angket pada siswa SBK Bina Anak Bangsa dari kelas VI SD sampai XII SMA. Hasil yang didapat dari validasi aplikasi menggunakan skala pengukuran Guttman ini mendapatkan nilai $90 \%$ untuk sisi ahli materi, dan $88,9 \%$ untuk siswa SBK Bina Anak Bangsa, sehingga aplikasi CAI pengenalan hewan berdasarkan klasifikasi makanan untuk anak berkebutuhan khusus dirasa telah sesuai dengan tujuan dalam memenuhi target pembelajaran.
\end{abstract}

Kata Kunci- Computer Assisted Instruction (CAI), Anak Berkebutuhan Khusus (ABK), Tutorial, Games, Pengenalan Hewan, Klasifikasi Makanan.

\section{PEndahuluan}

Anak berkebutuhan khusus atau anak luar biasa adalah anak yang menyimpang dari rata-rata anak normal dalam hal; ciri-ciri mental, kemampuan-kemampuan sensorik, fisik dan neuromaskular, perilaku sosial dan emosional, kemampuan berkomunikasi, maupun kombinasi dua atau lebih dari hal yang sudah disebutkan; sejauh ia memerlukan modifikasi dari tugas-tugas sekolah, metode belajar atau pelayanan terkait lainnya, yang ditunjukkan untuk pengembangan potensi atau kapasitasnya secara maksimal [1]. Anak berkebutuhan khusus juga bisa didefinisikan sebagai anak-anak yang tergolong abnormal yang menyandang ketunaan. Anak berkebutuhan khusus juga bisa tergolong sebagai anak yang berbakat [2].

Dalam proses pembelajaran di sekolah berkebutuhan khusus, salah satu pembelajaran yang diajarkan adalah pengenalan tentang hewan dalam mata pelajaran IPA. Materi pengenalan hewan juga diajarkan dalam terapi wicara untuk anak berkebutuhan khusus. Pada proses materi pengenalan hewan terkadang anak berkebutuhan khusus mengalami kesulitan untuk memahami materi tersebut. Beberapa anak berkebutuhan khusus juga terkadang mengalami kesulitan dalam mengeja dan melafalkan nama hewan yang akan mereka pelajari. Selama ini alat penunjang yang guru gunakan hanya buku lembar kerja siswa (LKS) dan buku yang khusus memuat materi tentang pengenalan hewan. Untuk kasus tertentu, para terapis untuk anak berkebutuhan khusus menggunakan alat bantu berupa kartu bergambar untuk mengenalkan hewan- 
hewan yang akan dipelajari anak berkebutuhan khusus. Membawakan materi pengenalan hewan pada anak berkebutuhan khusus tidak bisa menggunakan metode yang monoton. Karena metode penyampaian yang monoton mengakibatkan anak malas bahkan sampai tidak tertarik untuk belajar.

Dalam penyampaian pembelajaran untuk anak berkebutuhan khusus agar menjadi menarik, dibutuhkan sebuah media dalam proses pembelajaran. Media pembelajaran ini cenderung diartikan sebagai alat-alat grafis, photografis, atau elektronis untuk menangkap, memproses, dan menyusun kembali informasi visual atau verbal. Suatu proses pembelajaran yang baik dan berkualitas. Ada beberapa komponen yang sangat menentukan, antara lain tujuan pembelajaran, bahan belajar, metodologi pembelajaran, dan evaluasi pembelajaran. Ada dua aspek yang amat penting dalam metodologi pembelajaran. Yaitu model pembelajaran dan media pembelajaran. Kedua aspek ini saling berkaitan satu sama lainnya. Pemilihan salah satu model pembelajaran tertentu akan mempengaruhi jenis media pembelajaran yang sesuai [3].

Computer Assisted Instruction (CAI) adalah suatu bentuk pembelajaran yang menempatkan komputer sebagai piranti sistem pembelajaran individual, di mana siswa dapat berinteraksi langsung dengan sistem komputer yang sengaja dirancang atau dimanfaatkan oleh guru. Proses pembelajaran berupa sofware komputer yang meliputi: judul, tujuan, materi pembelajaran dan evaluasi pembelajaran. Model CAI yang dikembangkan yaitu drill and practice, tutorial, simulasi dan instructional games harus berorientasi pada tujuan pembelajaran bagi kepada standar kompetensi, kompetensi dasar dan indikator yang dicapai pada setiap kegiatan pembelajaran [4] Pembelajaran CAI dalam pembelajaran dapat meningkatkan pemahaman konsep dan movitivasi belajar. Selain itu juga dapat menghubungkan dan memperkuat teori, meningkatkan antusiasme belajar anak melalui interaktivitas, meningkatkan kemampuan teknologi informasi dan mampu memberikan umpan balik [5].

Berdasarkan latar belakang tersebut maka muncul gagasan untuk membuat aplikasi CAI pembelajaran interaktif dalam pengenalan hewan pada anak berkebutuhan khusus. Model pembelajaran yang akan disampaikan ini adalah model tutorial dan game sehingga anak berkebutuhan khusus dapat belajar tentang pengenalan hewan dan dapat bermain dengan sebuah game selingan.

\section{URAIAN PENELITIAN}

\section{A. Anak Berkebutuhan Khusus}

Anak berkebutuhan khusus (ABK) diartikan sebagai individu-individu yang mempunyai karakteristik yang berbeda dari individu lainnya yang dipandang normal oleh masyarakat pada umumnya. Secara lebih khusus anak berkebutuhan khusus menunjukkan karakteristik fisik, intelektual, dan emosional yang lebih rendah atau lebih tinggi dari anak normal sebayanya atau berada di luar standar normal yang berlaku di masyarakat. Sehingga mengalami kesulitan dalam meraih sukses baik dari segi sosial, personal, maupun aktivitas pendidikan [6]. ABK juga didefinisikan sebagai anak dengan karakteristik khusus yang berbeda dengan anak pada umumnya tanpa selalu menunjukkan pada ketidak mampuan mental, emosi, atau fisik [7]. ABK adalah anak yang secara signifikan berbeda dalam beberapa dimensi yang penting dari fungsi kemanusiaannya. Mereka yang secara fisik, psikologis, kognitif, atau sosial terlambat dalam mencapai tujuantujuan atau kebutuhan dan potensinya secara maksimal, meliputi mereka yang tuli, buta, gangguan bicara, cacat tubuh, retardasi mental, gangguan emosional, juga anakanak berbakat dengan inteligensi tinggi termasuk kedalam kategori anak berkebutuhan khusus karena memerlukan penanganan dari tenaga profesional terlatih [8]. Penyimpangan yang menyebabkan ABK berbeda terletak pada perbedaan ciri mental, kemampuan sensori, fisik dan neuromoskuler, perilaku sosial dan emosional, kemampuan berkomunikasi, maupun kombinasi dua atau tiga dari halhal tersebut [1].

Berdasarkan beberapa definisi yang telah diberikan, ABK dapat didefinisikan sebagai individu yang memiliki karakteristik fisik, intelektual, maupun emosional, di atas atau di bawah rata-rata individu pada umumnya. Anak berkebutuhan khusus diklasifikasikan apabila termasuk kedalam salah satu atau lebih dari kategori berikut ini [9].

1. Kelainan sensori, seperti cacat penglihatan atau pendengaran.

2. Deviasi mental, termasuk gifted dan retardasi mental.

3. Kelainan komunikasi, termasuk problem bahasa dan ucapan.

4. Ketidak mampuan belajar, termasuk masalah belajar yang serius karena kelainan fisik.

5. Perilaku menyimpang, termasuk gangguan emosional.

6. Cacat fisik dan kesehatan, termasuk kerusakan neurologis, ortopedis, dan penyakit lainnya seperti leukimia dan gangguan perkembangan.

\section{B. Hewan}

Hewan merupakan organisme eukariotik (organisme dengan sel kompleks) yang multiseluler (memiliki banyak sel). Secara garis besar, hewan dapat dikelompokkan menjadi dua golongan, yaitu golongan vertebrata (hewan bertulang belakang) dan golongan invertebrata (hewan tak bertulang belakang). Berbeda dengan tumbuhan, hewan tidak memiliki klorofil sehingga tidak dapat melakukan fotosintesis untuk membuat makanannya sendiri. Oleh karena itu, hewan harus mencari makanannya sendiri untuk mendapatkan energi kemudian makanan tersebut dicerna di 
dalam tubuhnya. Proses ini membutuhkan oksigen dan mengeluarkan karbon dioksida sebagai zat sisa.

\section{Media Pembelajaran}

Kata media berasal dari bahasa latin dan merupakan bentuk jamak dari kata medium yang secara harfiah berarti perantara atau pengantar. Kata kunci media adalah perantara. Dalam aktivitas pembelajaran, media dapat didefinisikan sebagai sesuatu yang dapat membawa informasi dan pengetahuan dalam interaksi yang berlangsung antara pendidik dengan peserta didik [10]. Media pembelajaran adalah berbagai jenis komponen dalam lingkungan siswa yang dapat merangsang siswa untuk belajar. Jadi, Media merupakan alat bantu yang digunakan guru dengan desain yang disesuaikan untuk meningkatkan kualitas belajar yang berfungsi untuk menjelaskan sebagian dari keseluruhan program pembelajaran yang sulit dijelaskan secara verbal [11]. Klasifikasi Media Pembelajaran adalah sebagai berikut [12].

- Media Berbasis Visual

- Media Berbasis Audio-Visual

- Media Berbasis Komputer

\section{Computer Assisted Instruction (CAI)}

Istilah pembelajaran berbantuan komputer diterjemahkan dari CAI (Computer-Assisted Instruction), sering juga digunakan secara bergantian dengan istilah CBL (Computer-Based Learning) dan CBI (ComputerBased Instruction) [13]. Pembelajaran berbasis komputer (Computer Based Instruction) menunjuk pada semua software pendidikan yang diakses melalui komputer di mana siswa dapat berinteraksi dengannya, salah satunya multimedia interaktif. Proses pembelajaran akan lebih efektif jika melibatkan aktivitas indera [14]. Hal tersebut merupakan modalitas yaitu audio, visual dan kinestetik yang bila dioptimalkan dapat mempengaruhi konsentrasi siswa belajar [15]. Karakteristik multimedia interaktif dalam pembelajaran yaitu [16].

1. Memiliki lebih dari satu media yang konvergen.

2. Bersifat interaktif.

3. Bersifat mandiri.

Model pembelajaran yang diterapkan dalam pembelajaran berbantuan komputer secara umum dapat diklasifikasikan menjadi empat model, yaitu model Tutorial (Penjelasan), model Drill and Practice (Latihan dan Praktek), model Simulation (Simulasi), dan model Game (Permainan) [17].

\section{E. Storyboard}

Storyboard adalah bentuk-bentuk gambar yang disiapkan disertai dengan penjelasan-penjelasan atau narasi. Penulisan storyboard sebaiknya diisi unsur visual terlebih dahulu baru kemudian unsur narasi dan audionya yaitu untuk melengkapi hal-hal yang sulit diungkapkan dalam bentuk visual sehingga harus diperkuat dengan narasi dan background audio atau sound FX [18].

\section{F. Skala Pengukuran Guttman untuk Validasi}

Skala pengukuran merupakan kesepakatan yang digunakan sebagai acuan untuk menentukan panjang pendeknya interval yang ada dalam alat ukur, sehingga alat ukur tersebut bila digunakan dalam pengukuran akan menghasilkan data kuantitatif [19]. Pada skala pengukuran Guttman akan didapat jawaban yang tegas, yaitu "yatidak"; "benar-salah"; "pernah-tidak pernah"; "positifnegatif', dan lain-lain.

Selain dapat dibuat dalam bentuk pilihan ganda, Skala Guttman juga dapat dibuat dalam bentuk checklist. Jawaban dapat dibuat skor tertinggi satu dan terendah nol. Misalnya untuk jawaban setuju diberi skor 1 dan tidak setuju diberi skor 0 . Analisa dilakukan dengan menggunakan rumus sebagai berikut:

$$
\begin{aligned}
& \mathrm{p}=(\mathrm{f} / \mathrm{n}) * 100 \% \\
& \text { Keterangan: } \\
& \mathrm{p}=\text { Nilai persentase yang dicari } \\
& \mathrm{f}=\text { Jumlah frekuensi dikalikan dengan skor yang } \\
& \text { ditetapkan tiap jawaban } \\
& \mathrm{n}=\text { Skor ideal (skor tertinggi dikalikan dengan jumlah } \\
& \text { sampel) }
\end{aligned}
$$

\section{PERANCANGAN APLIKASI}

\section{A. Arsitektur Aplikasi}

Desain arsitektur aplikasi akan ditunjukkan pada Gambar 1 berikut.

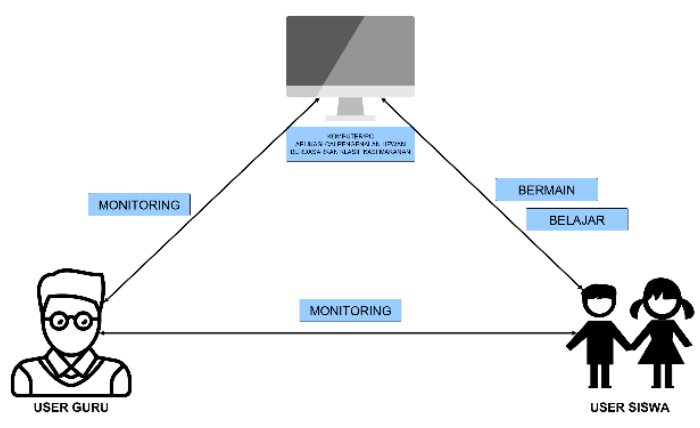

Gambar. 1 Arsitektur aplikasi

Aplikasi CAI Pengenalan Hewan Berdasarkan Klasifikasi Makanan ini tidak perlu koneksi internet, para siswa langsung bisa memainkan aplikasi pada laptop ataupun komputer, tanpa harus instal aplikasi (bersifat portable). Karena aplikasi berbasis CAI yang pada dasarnya dapat digunakan secara mandiri, para siswa dapat memainkan aplikasi sendiri. User siswa dapat bermain dan belajar pada komputer atau PC yang terdapat aplikasi pengenalan hewan, namun juga harus didampingi oleh guru 
yang mengajar. Aplikasi ini terdapat materi ajar yang akan dimonitoring oleh user guru yang mengajar.

\section{B. Hirarki Antar Muka Aplikasi}

Hirarki antarmuka aplikasi dapat dilihat pada Gambar 2 berikut.

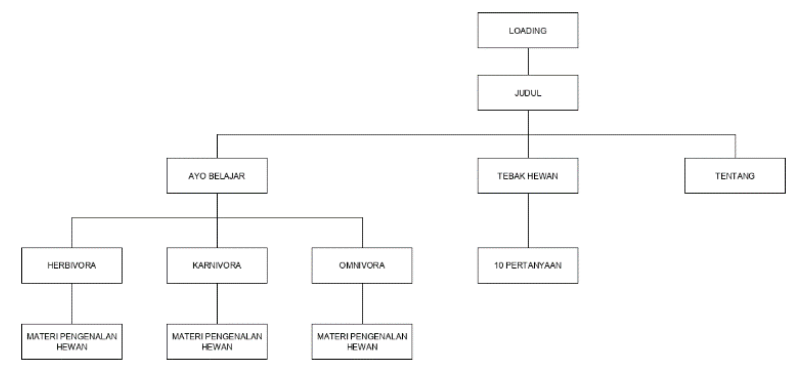

Gambar. 2 Hirarki antar muka aplikasi

Ketika aplikasi dibuka, aplikasi akan masuk ke halaman loading, kemudian ke halaman judul. Di halaman judul ini terdapat dua buah tombol yang terdiri dari tombol "Ayo Belajar" dan "Tebak Hewan". Setelah memilih tombol "Ayo Belajar", di halaman tersebut terdapat tiga buah tombol, yaitu "Herbivora", "Karnivora", dan "Omnivora". Tiap klasifikasi memiliki daftar hewan yang berbeda sesuai dengan jenis makanannya. Sedangkan halaman "Tebak Hewan" akan menampilkan 10 pertanyaan dalam bentuk seperti pilihan ganda. Pengguna akan mendengarkan suara hewan yang keluar, kemudian pengguna harus menjawab dengan benar hewan apakah itu.

\section{Analisis Kebutuhan}

Analisis kebutuhan sistem dilakukan dengan melakukan observasi terhadap sistem pembelajaran yang sedang berjalan pada sekolah. Kebutuhan fungsional sistem adalah kebutuhan yang berisi proses apa saja yang nantinya akan dilakukan oleh sistem. Dari sistem yang ada saat ini maka dapat ditentukan kebutuhan fungsional yang diperlukan pada aplikasi Computer Assisted Instruction (CAI) pengenalan hewan yang akan dibuat. Kebutuhan fungsional dapat dilihat pada Tabel 1 berikut.

TABEL I

FUNGSIONALITAS SISTEM

\begin{tabular}{|c|l|}
\hline KODE & \multicolumn{1}{|c|}{ DESKRIPSI } \\
\hline FR-01 & Sistem dapat menampilkan logo dan animasi loading. \\
\hline FR-02 & $\begin{array}{l}\text { Sistem dapat menampilkan judul, menu belajar } \\
\text { pengenalan hewan dan menu permainan tebak hewan. }\end{array}$ \\
\hline FR-03 & $\begin{array}{l}\text { Sistem dapat menampilkan menu klasifikasi } \\
\text { makanannya berupa karnivora, herbivora, dan } \\
\text { omnivora. }\end{array}$ \\
\hline FR-04 & $\begin{array}{l}\text { Sistem dapat menampilkan beberapa objek hewan } \\
\text { berdasarkan klasifikasi makannya. }\end{array}$ \\
\hline
\end{tabular}

\begin{tabular}{|c|l|}
\hline FR-05 & $\begin{array}{l}\text { Sistem dapat menampilkan keterangan dari salah satu } \\
\text { objek hewan. }\end{array}$ \\
\hline FR-06 & $\begin{array}{l}\text { Sistem dapat menampilkan pilihan permainan Tebak } \\
\text { Hewan. }\end{array}$ \\
\hline FR-07 & $\begin{array}{l}\text { Sistem dapat menampilkan 10 pertanyaan tebak } \\
\text { gambar dalam bentuk seperti pilihan ganda. }\end{array}$ \\
\hline FR-08 & $\begin{array}{l}\text { Sistem dapat menampilkan model permainan tebak } \\
\text { gambar dari salah satu level dengan skor pada aturan } \\
\text { yang telah ditentukan. }\end{array}$ \\
\hline FR-09 & \begin{tabular}{l} 
Sistem dapat menampilkan tentang atau profil. \\
\hline
\end{tabular} \\
\hline
\end{tabular}

D. Storyboard dan Implementasi Aplikasi

Storyboard dan Implementasi Aplikasi dapat dilihat pada Tabel 2 berikut.

TABEL II

STORYBOARD DAN IMPLEMENTASI APLIKASI

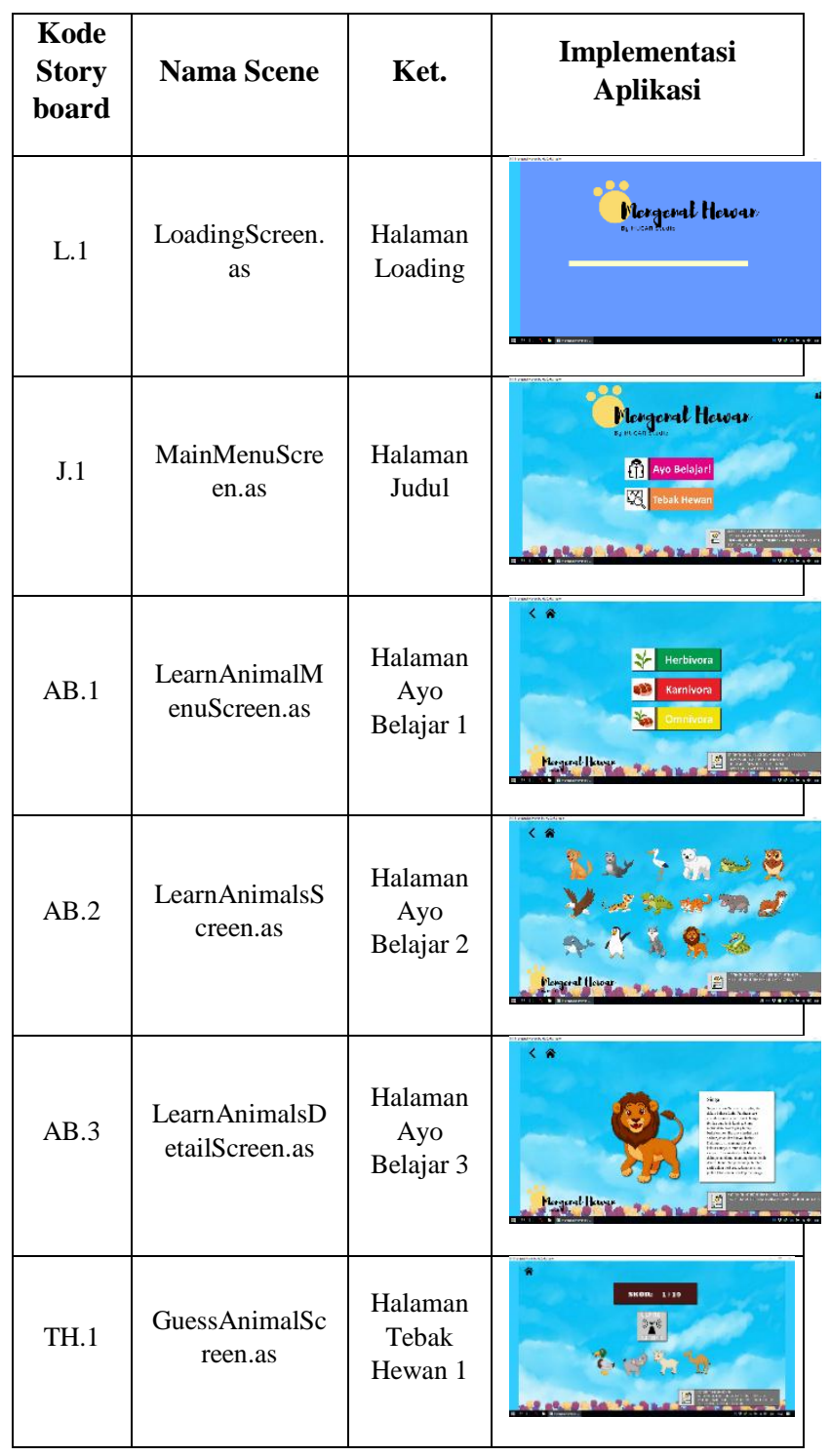




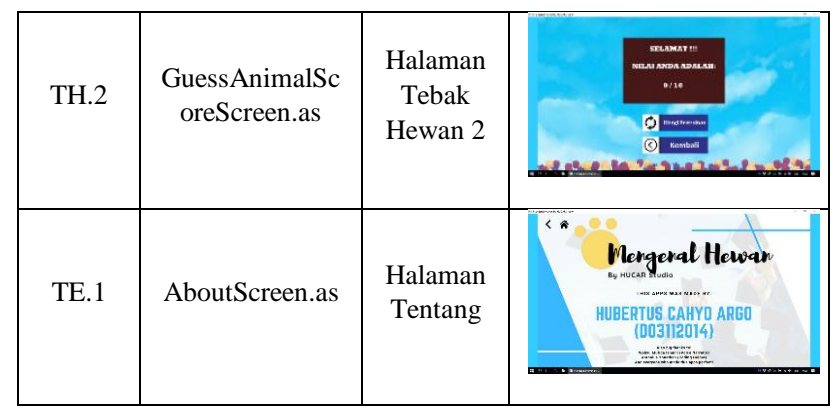

1) L.1 Antar Muka Aplikasi: Halaman pertama saat aplikasi dibuka, user dapat melihat Halaman Loading di mana aplikasi sedang memuat semua aset untuk masuk ke Halaman Judul.

2) J.1 Antar Muka Aplikasi: Di halaman ini terdapat tombol "Ayo Belajar!" untuk menuju ke Halaman Ayo Belajar 1 dan tombol permainan "Tebak Hewan" untuk menuju ke Halaman Tebak Hewan 1. Di halaman ini juga terdapat tombol "About Me" untuk menampilkan biodata pembuat aplikasi. Musik latar belakang akan mulai diputar sejak halaman ini dimulai, dan akan diputar berulang-ulang (looping). Serta audio narasi akan mulai terdengar setiap kursor diarahkan di salah satu tombol.

3) AB.1 Antar Muka Aplikasi: Ada tiga tombol pilihan yang ada pada halaman ini, yaitu tombol "Herbivora","Karnivora", dan "Omnivora". Setiap pilihan tombol diatas akan menuju ke Halaman Ayo Belajar 2. Halaman Ayo Belajar 1 juga terdapat tombol "Kembali" untuk kembali ke Halaman Judul dan tombol "Rumah" untuk kembali ke Halaman Judul. Audio narasi juga akan terdengar setiap kursor diarahkan di salah satu tombol.

4) AB.2 Antar Muka Aplikasi: Menampilkan daftar hewan-hewan yang ingin dipelajari sesuai dengan klasifikasi makanan yang telah dipilih di Halaman Ayo Belajar 1 (AB.1). Halaman Ayo Belajar 2 juga terdapat tombol "Kembali" untuk kembali ke Halaman Ayo Belajar 1 (AB.1) dan tombol "Rumah" untuk kembali ke Halaman Judul (J.1). Audio narasi juga akan terdengar setiap kursor diarahkan di salah satu tombol.

5) AB.3 Antar Muka Aplikasi: Menampilkan hewan yang ingin dipelajari secara spesifik, serta keterangan singkat dari hewan yang ingin dipelajari tersebut. Halaman Ayo Belajar 3 disertai tombol "Kembali" untuk kembali ke Halaman Ayo Belajar 2 (AB.2) dan tombol "Rumah" untuk kembali ke Halaman Judul (J.1). Audio narasi juga akan terdengar setiap kursor diarahkan di salah satu tombol. Jika kursor menekan gambar hewan tersebut, makan akan terdengar suara dari hewan tersebut.

6) TH.1 Antar Muka Aplikasi: Dalam Halaman Tebak Hewan 1 ini, user akan dihadapi dalam sebuah permainan tebak hewan berdasarkan suara hewan yang akan keluar. Pemain diharuskan mencocoki antara audio suara hewan yang keluar dan tebakan hewan. Pemain akan diberi 10 pertanyaan, serta 4 opsi jawaban yang bisa ditebak. Halaman Tebak Hewan 1 disertai tombol "Rumah" untuk kembali ke Halaman Judul. Audio hewan dapat diulang dalam tombol "Ulangi Suara".

7) TH.2 Antar Muka Aplikasi: Menampilkan skor user jika pengguna telah menyelesaikan permainan. Halaman Tebak Hewan 2 disertai tombol "Ulangi Permainan" untuk mengulangi permainan tebak hewan dan kembali ke Halaman Tebak Hewan 1 (TH.1) dan tombol "Kembali" untuk kembali ke Halaman Judul (J.1). Audio narasi juga akan terdengar setiap kursor diarahkan di salah satu tombol.

8) TE.1 Antar Muka Aplikasi: Pada Halaman Tentang terdapat informasi singkat perihal pembuat aplikasi. Halaman Tentang juga terdapat tombol "Kembali" dan "Rumah". Audio narasi juga akan terdengar setiap kursor diarahkan di salah satu tombol.

\section{E. Analisis Hasil Uji Coba dan Validasi Aplikasi}

Aplikasi CAI yang berjudul "Aplikasi Computer Assisted Instruction (CAI) Pengenalan Hewan Berdasarkan Klasifikasi Makanan Untuk Anak Berkebutuhan Khusus" dapat diimplementasikan pada laptop atau komputer secara offline dengan membuka aplikasi bernama "Mengenal Hewan.exe". File aplikasi ini bersifat portable dan dapat langsung dimainkan di laptop atau komputer setelah menginstall Adobe AIR. Aplikasi ini juga terdapat audio sehingga laptop atau komputer yang digunakan harus memiliki speaker agar user dapat mendengarkan suara lafal pengucapan nama hewan dan suara hewan.

Uji coba aplikasi dilakukan oleh satu orang ahli dan anak kelas VI SD sampai XII SMA, untuk memvalidasi aplikasi yang bertujuan untuk mengecek kelayakan aplikasi sebagai media pembelajaran yang ditinjau dari 2 sisi, yaitu: sisi materi dan sisi user (siswa). Validasi penelitian dilakukan oleh satu orang validator ahli materi (guru SLB Bina Anak Bangsa) dan pada anak kelas VI SD sampai XII SMA dengan menggunakan skala pengukuran Guttman, yaitu setiap pertanyaan hanya berisi dua pilihan jawaban, "Ya" atau "Tidak". Jawaban "Ya" artinya setuju diberi skor 1 dan jawaban "Tidak" artinya tidak setuju diberi skor 0 . Analisis kemudian dilakukan dengan menggunakan rumus perhitungan yaitu sebagai berikut:

$P=\frac{f}{n} x 100 \%$

Pada penelitian ini jumlah frekuensi adalah banyaknya atau jumlah validator pada setiap sisi uji validasi. Ada 1 orang validator pada setiap sisi, sehingga:

$\mathrm{f}=1$ * jumlah jawaban "Ya"

$\mathrm{n}=$ Skor ideal pada setiap sisi uji validasi jika semua pertanyaan dijawab "Ya" atau jumlah pertanyaan dikalikan jumlah sampel (sampel penelitian ini adalah validator pada setiap sisi pengujian). 
n pada uji validasi dari sisi materi (guru SLB Bina Anak Bangsa) $=10$

n pada uji pengguna dari sisi anak kelas VI SD sampai XII SMA $=18$

Perhitungan yang digunakan adalah skala Guttman dengan pendekatan kuantitatif hasil pengukuran di bawah $50 \%$ "mendekati tidak setuju" dan di atas 50\% "mendekati setuju" [20].

1) Validasi Ahli Materi (Guru SLB): Hasil validasi dari validator guru SLB Bina Anak Bangsa Pontianak. Berikut ini adalah hasil persentase uji validasi pada ahli materi, yaitu:

$$
\begin{aligned}
P & =\frac{f}{n} \times 100 \% \\
& =\frac{(1 \times 9)}{10} \times 100 \% \\
& =90 \%
\end{aligned}
$$

Berdasarkan persentase tersebut, maka dapat disimpulkan bahwa penilaian terhadap sisi materi Guru SLB Bina Anak Bangsa pada aplikasi ini dirata-ratakan adalah sebesar $90 \%$ yang bisa dikategorikan mendekati nilai $100 \%$. Aplikasi ini terbukti layak (mendekati setuju) dan telah memenuhi sebagian besar kriteria aplikasi pembelajaran yang sesuai dengan siswa SLB Bina Anak Bangsa Pontianak.

2) Validasi Anak Kelas VI SD sampai XII SMA: Hasil uji coba pada anak kelas VI SD sampai XII SMA di SLB Bina Anak Bangsa Pontianak. Berikut ini merupakan hasil uji kelayakan user pada anak kelas VI SD sampai XII SMA, yaitu:

\section{Presentase (\%)}

$$
\begin{aligned}
& =\frac{\text { EJumlahYA }}{\sum \text { Jumlah Jawab YA } \times \text { Responden }} \times 100 \% \\
& =\frac{176}{18 \times 11} \times 100 \% \\
& =\frac{176}{198} \times 100 \% \\
& =88.9 \%
\end{aligned}
$$

Berdasarkan hasil perhitungan dengan skala Guttman bahwa aplikasi yang digunakan oleh anak kelas VI SD sampai XII SMA didapatkan rata-rata hasilnya adalah $88,9 \%$ dan presentase tersebut, maka dapat disimpulkan bahwa penelian terhadap kelayakan aplikasi yang digunakan oleh anak kelas VI SD sampai XII SMA dapat dirata-ratakan adalah $88,9 \%$ dan bisa dikategorikan mendekati $100 \%$. Aplikasi ini terbukti layak (mendekati setuju) dan telah memenuhi sebagian besar kriteria aplikasi pembelajaran yang sesuai dengan materi pembelajaran IPA tentang pengenalan hewan.

\section{KESIMPULAN/RINGKASAN}

Berdasarkan hasil analisis uji coba dan validasi terhadap Aplikasi CAI Pengenalan Hewan Berdasarkan Klasifikasi Makanan Untuk Anak Berkebutuhan Khusus, dapat disimpulkan bahwa:

1. Penelitian berhasil membuat sebuah aplikasi CAI tentang pengenalan hewan karena berdasarkan hasil uji aplikasi, aplikasi ini mendapatkan nilai $90 \%$ untuk ahli Materi dan nilai $88,9 \%$ untuk uji coba pada anak kelas VI SD sampai XII SMA.

2. Aplikasi pembelajaran berbasis CAI dengan model tutorial dan instructional games lebih alternatif dibandingkan dengan metode belajar manual pada materi pengenalan hewan dalam buku maupun alat bantu berupa kartu bergambar. Aplikasi ini dapat membantu siswa SLB Bina Anak Bangsa Pontianak dalam memahami materi pembelajaran pengenalan hewan dalam mata pelajaran IPA.

\section{REFERENSI}

[1] F. Mangunsong, Psikologi dan Pendidikan Anak Berkebutuhan Khusus, Jilid I. Jakarta: LPSP3UI, 2009.

[2] M. Abdurrahman, Pendidikan Bagi Anak Berkesulitan belajar. Jakarta: Rineka Cipta, 2006.

[3] N. Sudjana and A. Rivai, Media Pengajaran. Bandung: Sinar Baru Algensindo, 2011.

[4] I. Jong, N. Prihartini, and T. Tursina, "Aplikasi Computer Assisted Instruction (CAI) Crafting Interior Rumah Bagi Anak Usia Dini," J. Sist. dan Teknol. Inf., vol. 6, no. 1, p. 1, 2017.

[5] N. Maulida, H. Anra, and H. S. Pratiwi, "Aplikasi Pembelajaran Interaktif Pengenalan Hewan pada Anak Usia Dini," J. Sist. dan Teknol. Inf., vol. 6, no. 1, p. 26, 2018.

[6] B. S. Bachri, "Meyakinkan Validitas Data Melalui Triangulasi Pada Penelitian Kualitatif," Teknol. Pendidik., 2010.

[7] E. W. Heward, Exceptional Children, An Introduction to Special Education. New Jersey: New Jersey: Merrill, Prentice Hall, 2009.

[8] C. R. Semiawan and F. Mangunsong, Keluarbiasaan Ganda (Twice Exceptionality): Mengeksplorasi, Mengenal, Mengidentifikasi, dan Menanganinya. Jakarta: Kencana Prenada Media Group, 2010.

[9] S. B. Thalib, Psikologi Pendidikan Berbasis Analisis Empiris Aplikatif. Jakarta: Kencana, 2017.

[10] M. S. Sutikno and P. Fathurrohman, Strategi Belajar Mengajar Melalui Penanaman Konsep Umum \& Konsep Islami. Bandung: Refika Aditama, 2010.

[11] H. M. Musfiqon, Pengembangan Media dan Sumber Pembelajaran. Jakarta: PT. Prestasi Pustakaraya, 2012.

[12] A. Azhar, Media Pembelajaran. Jakarta: PT. Raya Grafindo Persada, 2008.

[13] C. Riyana, Pedoman Pengembangan Media Video. Jakarta: P3AI UPI, 2007.

[14] M. E. Porter and A. Maulana, Strategi Bersaing. Tanggerang: Karisma Publishing Group, 2008.

[15] S. Ahmad, "Teori Belajar Dan Pembelajaran Di Sekolah Dasar," Biomass Chem Eng, 2013.

[16] Munir, Multimedia Konsep \& Aplikasi Dalam Pendidikan. Bandung: Alfabeta, 2014.

[17] S. Padmanthara, "PEMBELAJARAN BERBANTUAN KOMPUTER (PBK) dan MANFAAT SEBAGAI MEDIA PEMBELAJARAN," TEKNO, 2004. 
[18] Rusman, Model-Model Pembelajaran. Jakarta: PT. Raja Grafindo Persada, 2013.

[19] Sugiyono, Metode Penelitian Kuantitatif, Kualitatif dan R\&D Bandung: Alfabeta, 2012.

[20] F. F. M. Sibarani, T. Tursina, and A. Perwitasari, "Aplikasi Pembelajaran Pengenalan Nama Pahlawan Indonesia berbasis Computer Assisted Instruction (CAI), 'J. Sist. dan Teknol. Inf., vol. 6, no. 2, p. $88,2018$. 